\title{
Artificial Saliva Spray
}

National Cancer Institute

\section{Source}

National Cancer Institute. Artificial Saliva Spray. NCI Thesaurus. Code C131900.

A spray formulation containing a saliva substitute, composed of potassium chloride, sodium chloride, magnesium chloride, calcium chloride, dipotassium phosphate and monopotassium phosphate, that has potential anti-xerostomia activity. Upon direct oral application of the artificial saliva spray, a protective film of moisture is deposited over the mucous membranes of the mouth, which relieves dryness of the mucous membranes and increases salivary flow. In addition, artificial saliva may help prevent chemotherapyor radiotherapy-induced oral mucositis. 